\title{
EL DERECHO DE PROPIEDAD SOBRE LA TIERRA EN LA NUEVA CONSTITUCION
}

\author{
DESARROLLO INTEGRAL AGRARIO Y MINIFUNDIO
}

\section{Guillermo Figallo Adrianzén}

El Título III de la nueva Constitución del Perú, dedicado al Régimen Económico, comprende el Capitulo VII que se ocupa especialmente del Régimen Agrario (artículos 1570. al 159o.).

Inicia el referido Capítulo el artículo 1570: concede caracter prioritario al "desarrollo integral" al sector agrario. A primera vista, este dispositivo se justifica plenamente, ya que es sabido por todos que se trata del Sector más deprimido de nuestra economía y su producción está destinada a la satisfacción de necesidades primarias de la población. Sin embargo, creemos necesarias ciertas precisiones, pues connotados comentaristas advierten que el desarrollo rural integrado representa la politica adoptada los grupos dominantes latinoamericanos en reemplazo de la Reforma Agraria cuyo fracaso han venido pregonando ruidosamente en los últimos años. Esta política consiste en la concentración de los escasos recursos con que cuentan los países sub-desarrollados en ciertas áreas seleccionadas para la mejor utilización de su potencial económico y una mayor eficiencia de los servicios públicos; pero, si se realiza dentro del marco limitado del minifundio no logra elevar significativamente el nivel de , vida de la mayoría sino que beneficia más a los ricos; $y$, en realidad, se persigue con ella la estabilización de los desequilibrios existentes.

Podría decirse que no hay este peligro en el Perú donde se ha realizado una reforma agraria radical; pero no es así, pues si bien ésta ha liquidado el latifundio, uno de sus más graves vacios ha sido el olvido dèl problema del minifundio.

\section{INVIOLABILIDAD DE LA PROPIEDAD}

De acuerdo con el "pluralismo económico que propugna la Constitución, el sistema económico nacional se sustenta en la "coexistencia de diversas formas de propiedad y de empresa" que puedan constituirse cumpliendo los requisitos que señala el orden jurídico (art. 112o.).

Asimismo, declara que "la propiedad cualquiera que fuese es "inviolable" y el Estado la "garantiza". Tradicionalmente las Constituciones inspiradas en la ideologia liberal proclaman la inviolabilidad de la propiedad que podría ser considerada superflua habida cuenta de que ésta es un atributo inherente a todo derecho que no puede ser violado ni por el Estado, ni por los particulares. Pero, el objeto de dicha declaración es poner énfasis en la importancia de la propiedad para el liberalismo que encuentra en la satisfacción del interés indi- 
vidual el mejor modo de realizar el interés general por lo que el hecho de haberla mantenido en la nueva Carta revela la decisión de no incorporar la figura de la nacionalización dentro de nuestro orden juridico y que en caso de conflicto entre el derecho de propieúad privacia y el interés colectivo, söio podrá recurrirse a la expropiación que tiene carácter compensatorio. Si la expropiación es por causa de Reforma Agraria la Constitución faculta para que el pago del justiprecio pueda diferirse en "plazos adecuados" y con intereses "reajustables periódicamente".

\section{GARANTIA CONSTITUCIONAL Y FORMAS DE PROPIEDAD SOBRE LA TIERRA}

Cuando se trata del derecho de propiedad sobre la tierra el artículo $157 \mathrm{o}$. de la Constitución circunscribe la antedicha "garantia" a ciertas modalidades de propiedad y la condiciona al cumplimiento de determinados requisitos. A este respecto debemos señalar previamente que, de acuerdo con la doctrina no debemos confundir los vocablos "derecho" y "garantia", pues ello equivale a establecer en el plano de la terminologia constitucional una iraceptable sinonimia entre libertad jurídica y sus medios de protección y amparo. Por consiguiente, es posible la existencia de otras formas de propiedad privada garantizada por la ley común, pues la Constitución no las prohibe. Más bien la norma constitucional tiene sentido contrario, es decir, que dentro de nuestro ordenamiento co no puede prohibirse la existencia de las modalidades de propiedad que garantiza. El texto del numeral comentado ha sido objeto de severas críticas porque confunde como formas de propiedad privada, tanto la propiedad individual como la propiedad cooperativa, comunal, autogestionaria y otras modalidades asociativas que son formas de la propiedad social, categoría genérica que responde a la evolución del concepto de propiedad en los años posteriores a la Segunda Guerra Mundial y se mantiene fiel a la concepción tradicional que divide el derecho en público y privado a los que curresponden la propiedad privada y la propiedad estatal, sin admitir este "tertium gens" que es la propiedad social cuyo titular no es el Estado, ni participa de todos los atributos clásicos de la propiedad privada.

La propiedad privada "individual" en sentido jurídico es aquella en que el poder pleno sobre la cosa en que recae corresponde a una persona privada sea natural o colectiva a diferencia de la propiedad común o condominio. La posibilidad de que la frase propiedad privada individual haya sido empleada por el art. 1570 . en esta acepción puede encontrarse que las otras formas garantizadas son personas juridicas de derecho social. De donde resultaría que no solamente la Constitución no prohibe a las personas juridicas privadas ser propietarias de tierras contradiciendo los avances del Derecho Agrario sino que inclusive las garantizaria.

\section{LA FUNCION SOCIAL DE LA PROPIEDAD SOBRE LA TIERRA}

La Constitución establece de modo general que "la propiedad obliga a 
usar los bienes en armonia con el interés social" y cuando se refiere a la propiedad sobre la tierra reitera que debe ser conducida directamente "en armonia con el interés social", frase semejante al artículo 340. de la Constitución anterior por to que le alcanzaria la misma critica hecha a éste de haber establecido la función social sólo respecto a uno de los atributos de la propiedad que es uso, no asi en cuanto el disfrute y la disposición; y que es una norma imperfecta porque carece de sanción.

No creemos justificada esta crítica, pues, se desprende que la Constitución emplea el verbo "usar" en sentido amplio de "goce" del bien, que equivale al "valor de uso" en el lenguaje de los economistas.

La función social de la propiedad de la tierra de acuerdo con la doctrina actual, trasciende los tradicionales límites negativos impuestos por las relaciones de vecindad o en resguardo del interés público, que se reducen a "no hacer" (non facere) o "tolerar" (pati), pues implica obligaciones "de hacer" para el propietario por ser la tierra instrumento de cooperación social y de riqueza nacional. El derecho de propiedad deja de ser absoluto y adquiere un sentido relativo. No recae sobre la esencia de las cosas sino sobre su utilización. El fundamento de la propiedad es inseparable de su finalidad.

No obstante las acerbas críticas formuladas contra el principio de la función social, tanto de un extremo como del otro del pensamiento político, es indudable que ha sido desarrollado con resultados fecundos por la legislación de Reforma Agraria latinoamericana.

\section{EL ABANDONO DE LA TIERRA}

La función social, según la Constitución, impone dos tipos de obligaciones al propietario: a) el uso o explotación racionaí de la tierra; y b) la conducción directa.

El uso en armonia con el interés social no puede ser otro que la explotación racional por lo que el más grave incumplimiento de esta obligación es mantener la tierra inexplotada, inerte, abandonada. La Constitución reconoce esta consecuencia y sanciona el abandono de la tierra, pues declara que las tierras abandonadas "pasan" al dominio del Estado para su adjudicación a campesinos sin tierras. La extinción del derecho de propiedad por causa de abandono obedece a una tradición jurídica cuyos antecedentes remotos pueden encontrarse en la legislación de la Colonia fundada en una concepción patrimonial del dominio público (los territorios y riquezas de América pertenecían a la Corona por derecho propio). Partiendo del principio regaliano el sistema jurídico latinoamericano ha diseñado una doctrina propia de las tierras públicas expresada en el inciso 4c. del artículo 8220 . del Código Civil, aunque de modo imperfecto. En efecto, declara que son del Estado las tierras públicas entre las cuales se distinguen las "tierras sin dueño" que han pertenecido en el dominio originario del Estado y las tierras abandonadas. Respecto a las primeras existe una frondosa 
legislación sobre irrigaciones de tierras eriazas (aunque ambos conceptos no coinciden plenamente) y tierras de Selva. En cuanto a las segundas el Código Civil no precișa el requisito temporal o lapso que debe tränscurrir para que se produzca el abandono por lo que parecería que incurre en el error común entre muchos civilistas de confundir abandono con renuncia considerándolo una modalidad tácita de ésta.

Además, para la armonia con el interés social se requiere que la explotación de la tierra sea eficiente, es decir que se use de acuerdo con su finalidad económica. De ahi se deriva el principio de Derecho Agrario denominado del "buen cultivo" que significa una profunda transformación en el instituto juridico de la posesión cuando se trata de la tierra. Para que no exista abandono es necesario que la explotación se encuentre dirigida a la obtención de un rendimiento económico, lo que implica que solamente se considere acto posesorio el que consista en la explotación de la tierra de acuerdo con su mayor aptitud agrológica y que la posesión consista en el ejercicio de la actividad agrícola o ganadera, según la clase de tierras.

\section{LA CONDUCCION DIRECTA}

El segundo acápite del artículo $157 \mathrm{o}$. de la Constitución define la conducción directa diciendo que la hay "cuando el poseedor legítimo e inmediato tiene la dirección personal y la responsabilidad de la empresa". Este precepto agregado en las postrimerias del mandato de la Asamblea, después de un intenso debate en que fue interpretado de diferentes formas. Algunos asambleístas sostuvieron que la frase "conducción directa" era la expresión jurídica del postulado de la Reforma Agraria "la tierra para quien la trabaja". Otros advirtieron que la definición "se prestaba a una serie de interpretaciones a favor de los terratenientes". Hasta hubo quien enfatizó que evitaba "que se obligue al poseedor legitimo a que resida en el mismo fundo o quede amarrado a una radicación territorial. Ahora -concluyó- el conductor de la tierra podrá elegir libremente su domicilio", lo que significaría frustración de la Reforma Agraria.

Si analizamos la indicada definición de conducción directa nos encontramos que en el lenguaje de la Constitución los términos "poseedor, legítimo e inemdiato" tienen sentido distinto que para el Código Civil. Para el derecho civil poseedor legitimo es aquél que ejerce la posesión en virtud de un título válido, por lo que el poseedor legitimo son tanto el arrendatario, usufructuario, anticresista, como el propietario. En cambio es indudable que la Constitución identifica poseedor legítimo. El Código Civil define al poseedor inmediato como el "poseedor temporal en virtud de un derecho, correspondiendo la posesión mediata a quien le confirió el derecho" (art.8250.), mientras que para la Cons. titución, poseedor inmediato es el que ejerce los poderes del propietario personalmente. En otras palabras exige que el propietario ejerza la posesión de modo efectivo, y no por intermediación de otro. De cualquier modo ro resulta afortunada la expresión "poseedor legitimo e inmediato", pues se presta a confusiones. 
Para que haya conducción directa la Constitución exige además "la dirección personal" y "la responsabilidad de la empresa". De este modo el propietario queda obligado a organizar una unidad de produceión sobre la base del predio rústico del que es dueño y a convertirse en empresario. El centro de gravedad de la protección constitucional ha sido trasladado del título a la empresa agraria, la que también debe ser eficiente y contribuir al bien común extendiéndose a ésta el principio de la función social.

Empero la Constitución no exige la "habitualidad" o "profesionalidad" en la actividad agraria del propietario de la tierra, caracteristica esencial del empresario que originalmente exigía la Ley de la Reforma Agraria y que ha sido suprimido por la legislación reciente (decretos leyes Nos. 22747 y 22388) tanto respecto de los pequeños como de los grandes propietarios. En este aspecto la Constitución reproduce textualmente el texto del articulo 10. del Decreto Ley 22388.

Puede decirse que la dirección personal implica la habitualidad. No participamos de esta opinión por cuanto la dirección puede referirse únicamente a los actos juridicos-negociables externos de la empresa sin que abarque necesariamente los actos internos que significan el manejo del fundo propiamente di. cho que justifican la dedicación constante. En cuanto a la responsabilidad desde el punto de vista jurídico representa simplemente el riesgo de gozar las utilida. des o sufrir las pérdidas que resulten de la marcha de la empresa, pero tampoco exige "la condición de presencia" del propietario de la tierra. 